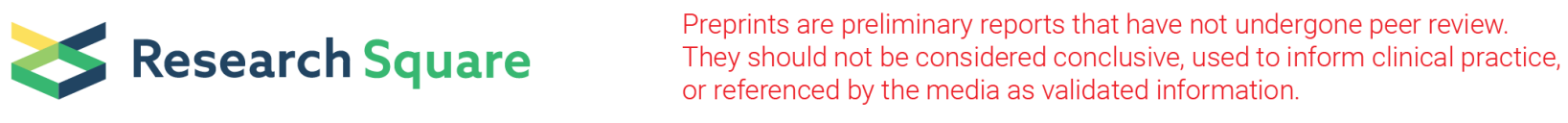

\title{
Asymptomatic Bacteriuria among Pregnant women in Addis Ababa, Ethiopia: Prevalence, Causal agents, and their Antimicrobial Susceptibility
}

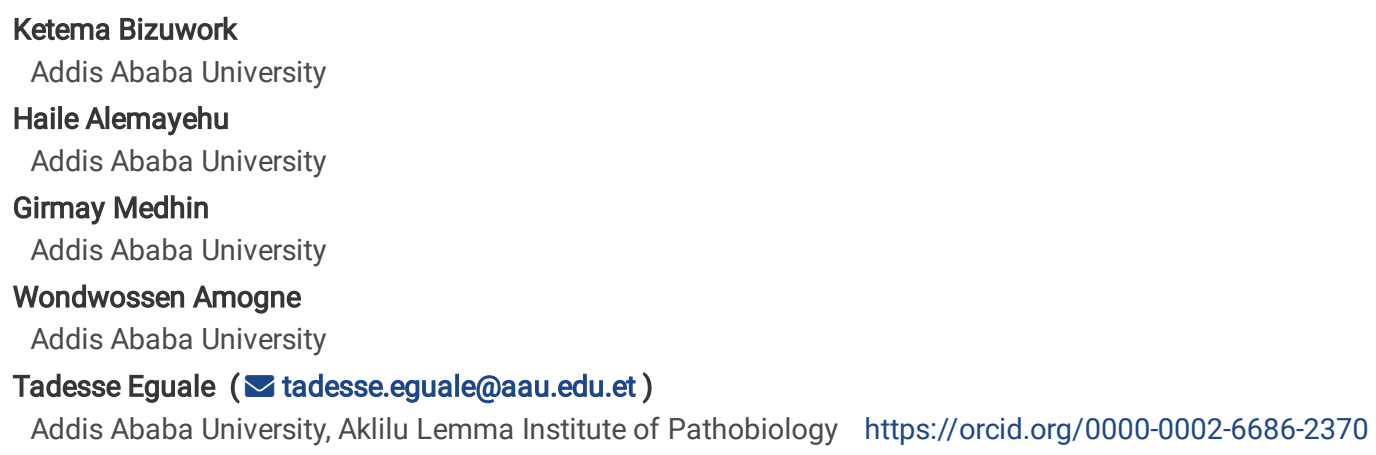

Research

Keywords: Antimicrobial susceptibility, Asymptomatic bacteriuria, Bacteria, Ethiopia, Pregnant women

Posted Date: December 7th, 2020

DOI: https://doi.org/10.21203/rs.3.rs-118280/v1

License: () (i) This work is licensed under a Creative Commons Attribution 4.0 International License. Read Full License 


\section{Abstract}

\section{Background}

Asymptomatic bacteriuria (ASBU) is an important health problem among pregnant women particularly in low income countries. This study aimed to estimate prevalence of ASBU, to identify causal bacterial pathogens and their antimicrobial susceptibility among pregnant women attending antenatal care centers in Addis Ababa, Ethiopia.

\section{Methods}

Health facility based cross-sectional study was conducted from March to May, 2019, where 281 pregnant women with no symptom of urinary tract infection were examined using standard microbiological techniques. Women whose urine sample carried greater than or equal to $10^{5}$ colony forming unit (CFU) of bacteria per milliliter was considered to have ASBU. Antimicrobial susceptibility of isolates was investigated using Kirby-Bauer disk diffusion method on Muller-Hinton agar plates.

\section{Results}

Out of 281 pregnant women examined, 44 (15.7\%) had ASBU and none of the factors tested in the current analysis were significantly associated with occurrence of ASBU ( $p<0.05)$. The most frequently isolated bacterial species were Escherichia coli $17(30.2 \%)$, Proteus, $13(23.2 \%)$ and Entrococcus $11(19.6 \%)$. All of the E. coli, Citrobacter and Klebsiela isolates and $84.6 \%$ of Proteus species were resistant to ampicillin. All bacterial isolates were resistant to at least one of antimicrobial agents tested. Resistance to three or more antimicrobials was detected in 15 (88.2\%) of E. coli, 10 (76.9\%) of Proteus, and 6 (54.6\%) of Entrococcus isolates. Resistance to as high as 7 antimicrobials among E. coli and Proteus isolates and 9 antimicrobials among Entercoccus isolates was detected.

\section{Conclusions}

Routine screening for ASBU during antenatal visit is likely to result in early treatment and minimize complication to the mother and fetus. Assess sensitivity of isolates to commonly prescribed antimicrobials rather than treating empirically is recommended.

\section{Background}

Asymptomatic bacteriuria (ASBU) is defined as existence of bacteria in urine at a load of $10^{5} \mathrm{CFU} / \mathrm{ml}$ or more in the absence of clinical symptoms of urinary tract infection [1, 2]. Although both gender and all age groups are prone to ASBU, it is more common in women due to proximity of female urethra to anus which facilitates colonization of the periurethral area with bacteria from gastrointestinal tract $[3,4]$. Its occurrence in women increases directly with sexual activity and in women of child-bearing age [4,5]. Diabetic patients, women with low level of educational status and those with history of urinary tract infection are reported to be at higher risk of developing ASBU[6]. Pregnant women are particularly prone to urinary tract infection and ASBU due to physiologic changes associated with pregnancy like smooth muscle relaxation, dilation of the ureters and renal pelvis which favor bacterial multiplication [7]. In addition, a general decline in immunity during pregnancy predisposes women to infection [8].

Pregnant women with ASBU suffer from various adverse outcomes. For instance, $50 \%$ of pregnant women with ASBU were reported to develop symptomatic urinary tract infection manifested by pyelonephritis followed by high rate of intrauterine growth restriction leading to low birth-weight infants, increased risk of preterm labor, pregnancy-induced hypertension, preeclampsia, amnionitis and anemia[9, 10]. Systematic review and metaanalysis showed strong association of ASBU with both type 1 and type 2 diabetes[11]. A prospective observational study among women with diabetes and ASBU also reported increased risk of hospitalization for urosepsis [12].

Prevalence of ASBU among pregnant women varies across different countries and it is more common in developing countries. In Africa, prevalence of $24.7 \%$ was reported from Nigeria[13], whereas in Ghana, prevalence of 5.5\% was reported [14]. Prevalence of $21.2 \%$ and $18.8 \%$ was reported from North and South Ethiopia $[15,16]$. The common bacteria isolated from pregnant women with ASBU, include Escherichia coli, Klebseilla species, Enterococcus faecalis, Proteus species, and Staphylococcus aureus [17-19]. Potential complications associated with ASBU are significantly decreased in pregnant women if treated with appropriate antimicrobials [20]. However, reports elsewhere show that pathogenic bacteria including uropathogens are developing resistance to antimicrobials, and multi-drug resistant strains are emerging rapidly posing major threat [21]. Understanding the rate of occurrence of ASBU among pregnant women, factors associated with its occurrence, identification of bacterial pathogens involved and their antimicrobial susceptibility is vital in advising clinicians on appropriate management of urinary tract infection and associated complications. Therefore, this study aimed to assess the occurrence of ASBU, factors associated with risk of ASBU, bacterial pathogens involved and their antimicrobial susceptibility among pregnant women attending antenatal care services in Addis Ababa, Ethiopia.

\section{Materials And Methods}

\section{Study area and study design}


This study was conducted in Addis Ababa, the capital city of Ethiopia from March to May, 2019. Health facility based cross-sectional study design was employed to recruit pregnant women by simple random sampling method from antenatal care centers of two government hospitals namely: Tikur Anbessa Speciallized Hospital (TASH) and Zewditu Memorial Hospital (ZMH) and two private health care facilities: Ananiya, and Hemon mother and child health care specialty centers located in Addis Ababa.

\section{Sample size determination and recruitment of study participants}

The sample size was calculated using single population proportion formula based on the previous report of $21.2 \%$ of ASBU in the northern Ethiopia [22]. With 95\% confidence interval, 10\% non-response rate and 5\% marginal error, the calculated sample size was 283.

First, total sample size calculated was allocated into the study hospitals proportional to the number of pregnant women attending selected antenatal care centers. Once clear explanation about the study was given to each pregnant women coming to antenatal care center for routine antenatal care service, they were requested to be involved in the study. Pregnant women excluded from the study were those $<18$ years of age, those with symptomatic urinary tract infection, who took two or more glasses of fluid one hour before clinic attendance, who were treated with antimicrobials during the last one week and women with current symptoms of sexually transmitted infections. Among those who volunteered to participate and fulfill the inclusion criteria, half of them were recruited randomly. Two rolled paper coded as number one, and zero were offered to participants to pick one and those who picked a rolled paper labeled with number one were recruited.

\section{Data and sample collection}

Information about age, residence, religion, marital status, educational status, monthly income, frequency of sexual intercourse per week, frequency of vaginal douching per day, history of urinary tract infection in this pregnancy; past history for chronic diseases (diabetes mellitus, hypertension), history of sexually transmitted diseases, stage of pregnancy and parity were collected from each woman through interview during sample collection. Current status of the pregnant women for HIV/AIDS and Hepatitis B surface antigen was reviewed from the recent information sheets of pregnant women's chart. After instructing the women to take perineal care, a clean-catch midstream urine samples were collected into sterile containers and transported to Microbiology Laboratory of Aklilu lemma Institute of Pathobiology in ice box within 3-4 hours of collection.

\section{Urine sample processing and pathogen isolation}

A loopful (10 micro liter) of well mixed urine sample was inoculated on to plate count agar and grown for $24 \mathrm{~h}$ at $37^{\circ} \mathrm{C}$. Number of colonies grown on each plate was counted to determine colony forming units per milliliter (CFU/ml) of the urine sample. A urine sample containing $\geq 10^{5} \mathrm{cfu} / \mathrm{ml}$ was considered as having ASBU [9] . For determination of the type of organisms involved, colonies from plate count agar plates were picked and inoculated to various selective media such as Eoseine Methylene Blue (EMB) agar to differentiate Escherchia coli, Klebsiella species, and Citrobacter species; Cystiene-lactose-electrolyte-deficient (CLED) medium to differentiate proteus species, biosculine agar and enterococcus agar to identify Enterococcus species after incubating for $24 \mathrm{hrs}$ at $37^{\circ} \mathrm{C}$. In addition, urine samples from women with ASBU were also directly plated to selective media. Further, biochemical tests like triple sugar iron agar, lysine iron agar, citrate, urease, indole, potassium hydroxide (KOH), and catalase tests were employed to further identify type of bacterial species involved[23-25].

\section{Investigation of antimicrobial susceptibility of bacterial isolates}

The antimicrobial susceptibility tests of the isolates were performed according to the Clinical Laboratory Standards Institute (CLSI) guideline[26] using Kirby-Bauer disk diffusion method on Muller-Hinton agar plates (Oxoid, CM0337 Basingstoke, England). The following antimicrobial (Sensi-Discs, Becton, Dickinson and Company, Loveton, USA) and disc potencies were used: amoxicillin + clavulanic acid (Amc) (20/10 $\mu \mathrm{g})$, ampicillin (Amp) (10 $\mu \mathrm{g})$, cephalothin (CF) $(30 \mu \mathrm{g})$, ceftriaxone (Cro) $(30 \mu \mathrm{g})$, ciprofloxacin (Cip) $(5 \mu \mathrm{g})$, gentamicin(Gm) $(10 \mu \mathrm{g})$, streptomycin(S) $(10 \mu \mathrm{g})$, sulfisoxazole (G), sulfamethoxazole+ trimethoprim (Sxt) $(23.75 / 1.25 \mu \mathrm{g})$, tetracycline (Te) $(30 \mu \mathrm{g})$, chloramphenicol (C), $(30 \mu \mathrm{g})$, vancomycin $(\mathrm{Va})(30 \mu \mathrm{g}), \mathrm{kanamycin}(\mathrm{K})$, $(30 \mu \mathrm{g})$ erthromycin (Ery) $(15 \mu \mathrm{g})$, Oxacillin, (ox), $(1 \mu \mathrm{g})$, clindamycin (DA) $(2 \mu \mathrm{g})$, penicillin (P) (10 $\mu \mathrm{g})$. Escherichia coli ATCC 25922 and Staphylococcus aureus ATCC25923 were used as a quality control organisms for gram negative and gram positive organisms, respectively. The interpretation of the categories of susceptible and resistant was based on the CLSI guidelines [26]. Isolates were regarded as multi-drug resistant (MDR) when they were resistant to at least two or more antimicrobials belonging to different classes [27].

\section{Data analysis}

Descriptive statistics: mean, standard deviation, frequency and percentage were used to summarize different variables. Logistic regression was used to model association of pre-defined independent variables with the binary outcome. P-value less than 0.05 was as indicator for statistical significance.

\section{Results}




\section{Prevalence of asymptomatic bacteriuria}

Out of 281 cultured urine samples, 44 had greater than or equal to $10^{5} \mathrm{cfu} / \mathrm{ml}$, resulting in $15.7 \%$ prevalence of ASBU with no significant difference between private health care institutions $(n=14 ; 18.0 \%)$ and government hospitals ( $n=30 ; 14.8 \%)$. Forty-one (16.6\%) married and $3(8.8 \%)$ unmarried pregnant women were positive for ASBU. Similarly, lower monthly income and being illiterate were associated with minor non-significant increase in occurrence of ASBU (Table 1).

Table 1

Association of demographic characteristic with ASBU, $N=281$

\begin{tabular}{|c|c|c|c|c|c|}
\hline Variables & No. tested & +ve for ASBU & $\operatorname{coR}(95 \% \mathrm{Cl})$ & AOR(95\%Cl) & $p$-Value \\
\hline \multicolumn{2}{|c|}{ Type of health facility } & No. (\%) & & & 0.34 \\
\hline Private & 78 & 14(18) & $1.03(0.50,2.12)$ & $0.62(0.23,1.66)$ & \\
\hline Government & 203 & $30(14.8)$ & $\star \star$ & & \\
\hline Age & & & & & 0.23 \\
\hline $18-24$ & 74 & $9(12.2)$ & $1.41(0.46,4.00)$ & $2.31(0.63,8.50)$ & \\
\hline $25-34$ & 166 & $28(16.9)$ & $0.78(0.30,201)$ & & \\
\hline $35-49$ & 41 & $7(17.1)$ & $\star \star$ & & \\
\hline Residence & & & & & 0.19 \\
\hline AA & 236 & $38(16.1)$ & $0.80(0.32,2.03)$ & $0.48(0.17,1.42)$ & \\
\hline OAA & 45 & $6(13.3)$ & $\star \star$ & & \\
\hline Religion & & & & & 0.88 \\
\hline Christian & 211 & $34(16.1)$ & $1.32(0.65,2.70)$ & $1.07(0.44,2.63)$ & \\
\hline Muslim & 70 & $10(14.3)$ & ** & & \\
\hline Marital status & & & & & 0.35 \\
\hline Married & 247 & $41(16.6)$ & $0.49(0.14,1.67)$ & $0.52(0.13,2.05)$ & \\
\hline Unmarried & 34 & $3(8.8)$ & $\star \star$ & & \\
\hline Educational sta & tus & & & & 0.64 \\
\hline Illiterate & 39 & $9(23.1)$ & $0.49(0.19,1.25)$ & $0.57(0.14,2.25)$ & \\
\hline Grade 1-12 & 133 & $20(15)$ & $0.79(0.38,1.63)$ & & \\
\hline$\geq$ College & 109 & $15(13.8)$ & $\star \star$ & & \\
\hline Income per mo & $\operatorname{th}(\mathrm{EB})$ & & & & 0.73 \\
\hline$\leq 2000$ & 101 & 19(18.8) & $0.70(0.36,1.34)$ & $0.87(0.39,1.92)$ & \\
\hline$>2000$ & 180 & $25(13.9)$ & $\star \star$ & ** & \\
\hline
\end{tabular}

$\mathrm{ETB}=$ Ethiopian birr, $\mathrm{AA}=$ Addis Ababa, OAA $=$ out of Addis Ababa, COR $=$ Crude Odds ratio, $\mathrm{AOR}=\mathrm{Adjusted}$ odds ratio, $\mathrm{Cl}=$ confidence interval, $* \star=$ reference

\section{Association of selected factors with the occurrence of ASBU}

Being younger age group $\mathrm{OR}=2.31(95 \% \mathrm{Cl}: 0.63,8.50)$, less frequency of vaginal douching per day $\mathrm{OR}=1.83(95 \% \mathrm{Cl}: 0.82,4.07)$, history of previous urinary tract infection in this pregnancy $\mathrm{OR}=1.23(95 \% \mathrm{Cl}: 0.59,2.58)$ were slightly more likely to be associated with the ASBU. However, none of the variables tested for association were statistically significant at $p<0.05$ (Table 3). Similarly, frequency of vaginal douching, frequency of sexual contact, history of chronic diseases, stage of pregnancy and other factors did not show statistically significant association with occurrence of ASBU (Table 2). 
Association of background and clinical characteristics with ASBU, $\mathrm{N}=281$

\begin{tabular}{|c|c|c|c|c|c|}
\hline Variables & $\begin{array}{l}\text { Tested } \\
\text { No. }\end{array}$ & $\begin{array}{l}\text { poitive for ASBU } \\
\text { No. (\%) }\end{array}$ & $\operatorname{COR}(95 \% \mathrm{Cl})$ & AOR(95\%Cl) & $\begin{array}{l}\mathrm{P} \text { - } \\
\text { Value }\end{array}$ \\
\hline \multicolumn{3}{|c|}{ Frequency Vaginal douching per day } & & & 0.14 \\
\hline$\leq$ Two times & 117 & $14(12)$ & $1.65(0.83,3.27)$ & $1.83(0.82,4.07)$ & \\
\hline$\geq$ Three times & 164 & $30(18.3)$ & $\star \star$ & & \\
\hline \multicolumn{3}{|c|}{ History of chronic disease } & & & 0.70 \\
\hline Yes & 52 & 10(19.2) & $0.86(0.39,1.96)$ & $0.84(0.34,2.07)$ & \\
\hline No & 229 & $34(14.8)$ & ** & & \\
\hline \multicolumn{3}{|l|}{ Parity } & & & 0.78 \\
\hline Primi para & 183 & $27(14.8)$ & $1.21(0.63,2.36)$ & $1.14(0.45,2.88)$ & \\
\hline Multi para & 98 & 17(17.3) & $\star \star$ & & \\
\hline \multicolumn{3}{|l|}{ Stage of pregnancy } & & & 0.83 \\
\hline First trimester & 103 & 19(18.4) & $0.77(0.35,1.66)$ & $0.90(0.35,2.34)$ & \\
\hline Second trimester & 90 & $12(13.3)$ & $1.13(0.48,2.63)$ & & \\
\hline Third trimester & 88 & 13(14.8) & ** & & \\
\hline \multicolumn{3}{|l|}{ Serology test status } & & & 0.15 \\
\hline+ Ve for HIV/AIDS & 13 & $3(23.1)$ & $0.61(0.16,2.30)$ & $0.33(0.75,1.48)$ & \\
\hline + Ve for HiBsAg & 14 & $2(14.3$ & $1.09(0.23,5.05)$ & & \\
\hline -Ve for both & 254 & $39(15.4)$ & ** & & \\
\hline \multicolumn{3}{|l|}{ VDRL test status } & & & 0.27 \\
\hline Positive & 18 & 2(11.1) & $3.32(0.43,25.63)$ & $3.00(0.39,27.77)$ & \\
\hline Negative & 236 & $42(17.8)$ & ** & & \\
\hline \multicolumn{4}{|c|}{ History of treatment for UTI in this pregnancy } & & 0.36 \\
\hline Yes & 89 & 13(14.6) & $1.23(0.59,2.58)$ & $1.51(0.62,3.67)$ & \\
\hline No & 192 & $31(16.1)$ & ** & $\star \star$ & \\
\hline \multicolumn{6}{|c|}{ Note: History chronic disease includes: Diabetes mellitus (DM), hypertension (HPT), and renal calculi (RC). } \\
\hline \multicolumn{6}{|c|}{$\begin{array}{l}\text { HIV/AIDS: Human immune-deficiency virus/acquired immunodeficiency syndrome, HiBsAg: hepatitis B surface antigen, ANC: Antenatal } \\
\text { care, No. = Number, }{ }^{\star *}=\text { Reference. }\end{array}$} \\
\hline
\end{tabular}

\section{Common bacterial pathogens isolated from pregnant women with ASBU}

A total of 56 bacterial pathogens were isolated from 44 pregnant women with ASBU of which 45(80.4\%) were gram negative, while the remaining 11 were gram positive organisms. The isolated bacterial species were E. coli: 17 (30.6\%) followed by Proteus spp., 13(23.2\%), Enterococcus spp., 11(19.6\%), Klebsiela spp., 8 (14.3\%) and Citrobacter spp., 7 (12.3\%). Among the 44 participants that were positive for ASBU, 15(34.1\%) were positive for more than one bacterial pathogens. The most frequent bacterial species that appeared jointly in single pregnant women's urine sample were $E$. coli, and Proteus.

\section{Antimicrobial susceptibility of bacterial isolates}

All of the E. coli, Citrobactrand Klebsiela isolates and $84.6 \%$ of Proteus were resistant to ampicillin. Similarly, 70.6\% of E. coli, 100\% of Citrobacter and Klebsiella isolates and $84.6 \%$ of Proteus species were resistant to cephalothin. High rate of resistance to other antimicrobials such as amoxicillin+clavulanic acid and sulfisoxazole was also recorded. Resistance to ceftriaxone was detected in $17.6 \%, 28.6 \%, 37.5 \%$, and $38.4 \%$ of $E$. coli, Citrobacter, Klebsiella and Proteus isolates respectively. All of the Enterocccus isolates were resistant to SXT, whereas $90.9 \%$ and $72.7 \%$ of the isolates 
were resistant to chlorampheicol and amikacin, respectively. Relatively low level of resistance to ciprofloxacin was observed in all species of bacteria isolated in the current study (Table 3).

Table 3

Antimicrobial susceptibility test result of bacteria isolated from pregnant women with $\mathrm{ASBU}(\mathrm{N}=56)$

\begin{tabular}{|c|c|c|c|c|c|c|c|c|c|c|c|c|}
\hline \multirow{2}{*}{$\begin{array}{l}\text { Bacterial } \\
\text { isolates }\end{array}$} & \multicolumn{12}{|c|}{ Antimicrobials tested No. and (\%) resistant } \\
\hline & TE & SXT & S & GM & AM & CRO & CIP & $\mathrm{CF}$ & C & AN & AMC & G \\
\hline $\begin{array}{c}\text { E. coli } \\
(\mathrm{N}=17)\end{array}$ & $3(17.6)$ & $1(5.9)$ & $4(23.5)$ & 2(11.8) & $17(100)$ & $3(17.6)$ & $1(5.9)$ & 12(70.6) & $1(5.9$ & $1(5.9)$ & 13(76.4) & $9(53)$ \\
\hline $\begin{array}{l}\text { Citrobacter } \\
\operatorname{spp},(\mathrm{N}=7)\end{array}$ & $1(14.3)$ & $1(14.3)$ & $4(57.1)$ & $0(0.0)$ & $7(100)$ & $\begin{array}{l}2 \\
(28.6)\end{array}$ & $0(0.0)$ & $7(100)$ & $0(0.0)$ & $3(42.9$ & $6(85.7)$ & $6(85.7)$ \\
\hline $\begin{array}{l}\text { Klebssiela } \\
\text { spp. }(\mathrm{N}=8)\end{array}$ & $0(0.0)$ & $2(25)$ & $2(25)$ & $1(12.5)$ & $8(100)$ & $3(37.5)$ & $1(12.5)$ & $8(100)$ & $1(12.5)$ & $1(12.5)$ & $8(100)$ & $3(37.5)$ \\
\hline $\begin{array}{l}\text { Proteus spp. } \\
(\mathrm{N}=13)\end{array}$ & $3(23.1)$ & $1(7.7)$ & $3(23.1)$ & $1(7.7)$ & 11(84.6) & $5(38.4)$ & $0(0.0)$ & 11(84.6) & $2(15.4)$ & $2(15.4)$ & $12(92.3)$ & $4(30.8)$ \\
\hline \multirow{2}{*}{$\begin{array}{l}\text { Enterococcus } \\
\text { spp. }(N=11)\end{array}$} & VA & $\mathrm{P}$ & ERY & CIP & C & CRO & $\mathrm{K}$ & CF & OX & DA & AMC & $\mathrm{GM}$ \\
\hline & $3(27.3)$ & $11(100)$ & $3(27.3)$ & 2(18.2) & $3(27.3)$ & $2(18.2)$ & $1(9.1)$ & $6(54.5)$ & 10(90.9) & $8(72.7)$ & $6(54.5)$ & $0(0.0)$ \\
\hline
\end{tabular}

$\mathrm{TE}=$ Tetracycline, SXT = Sulphamethoxazole +Trimethoprim, S = Streptomycin, GM = Gentamycine, $\mathrm{G}=$ Sulfisoxazole, $\mathrm{CRO}=\mathrm{Ceftriaxone}$, CIP = Ciprofloxacin, $\mathrm{CF}=$ Cephalothin, $\mathrm{C}=$ Chloramphenicol, $\mathrm{AN}=$ Amikacin, $\mathrm{AMC}=$ Amoxacillin + Clavulanic Acid, $\mathrm{AM}=\mathrm{Ampicillin}, \mathrm{Va}=\mathrm{Vancomycin}, \mathrm{P}=$ Penicillin, ERY = Erthromycin, $\mathrm{K}=$ kanamycin, $\mathrm{OX}=$ Oxacillin, $\mathrm{DA}=$ Clindamycin,, $\mathrm{G}=$ Sulfisoxazole

Resistance to 3 or more antimicrobials was detected in 15 (88.2\%), 10 (76.9\%), and 6 (54.6\%) of E. coli, Proteus and Entrococcus isolates, respectively. The common resistance pattern detected among $E$. coli isolates was resistance to G, CF, AM, AMC in 6 ( $35.6 \%)$ of the 17 isolates. Two $E$. coli isolates in the current study were resistant to 7 antimicrobials tested. Five (38.5\%) of Proteus isolates and one (12.5\%) of Klebsiela isolate were resistant to seven antimicrobials. Out of the eleven Enterococcus species isolated; eight (72.7\%) of them were resistant to two or more antimicrobials tested. One of the Enterococcus isolated from the pregnant women attending private antenatal care center was resistant to 9 antimicrobials (Table 4). 
Table 4

Antimicrobial resistance pattern of bacterial pathogens, $N=56$

\begin{tabular}{|c|c|c|c|c|}
\hline Bacterial species & Health facility & Resistance pattem & NRP & TNatbR \\
\hline \multicolumn{5}{|l|}{ E. coli (17) } \\
\hline & \multirow[t]{2}{*}{ TASH(06) } & TE, S, GM, CRO & 1 & 4 \\
\hline & & $\mathrm{G}, \mathrm{CF}, \mathrm{AMC}, \mathrm{AM}$ & 5 & 4 \\
\hline & \multirow[t]{3}{*}{$\mathrm{ZMH}(09)$} & CIP, TE, SXT, GM, CRO & 1 & 5 \\
\hline & & S & 2 & 1 \\
\hline & & G. CF, AM, AMC & 6 & 4 \\
\hline & Private(02) & CRO, G, TE, S, CF, AMC, AM & 2 & 7 \\
\hline \multicolumn{5}{|l|}{ Proteus Spp (13) } \\
\hline & TASH(04) & TE, SXT, S, GM, G, CRO, AN & 1 & 7 \\
\hline & & CF, AMC, AM & 3 & 3 \\
\hline & $\mathrm{ZMH}(08)$ & $\mathrm{CRO}, \mathrm{AN}, \mathrm{C}, \mathrm{TE}, \mathrm{AM}, \mathrm{AMC}, \mathrm{CF}$ & 5 & 7 \\
\hline & & $S, G$ & 3 & 2 \\
\hline & Private(01) & $\mathrm{CRO}, \mathrm{CF}, \mathrm{AM}, \mathrm{AMC}$ & 1 & 4 \\
\hline \multicolumn{5}{|c|}{ Enterococcus Spp(11) } \\
\hline & TASH(02) & $\mathrm{P}, \mathrm{OX}, \mathrm{DA}, \mathrm{CRO}, \mathrm{CF}, \mathrm{AMC}$ & 2 & 6 \\
\hline & $\mathrm{ZMH}(05)$ & $\mathrm{P}, \mathrm{DA}, \mathrm{C}, \mathrm{VA}, \mathrm{AMC}, \mathrm{CF}$ & 3 & 6 \\
\hline & & $\mathrm{OX}, \mathrm{P}$ & 2 & 2 \\
\hline & Private(04) & P, OX, DA, CF, AMC, VA, ERY, CRO, CIP & 1 & 9 \\
\hline & & $\mathrm{P}$ & 3 & 1 \\
\hline \multicolumn{5}{|l|}{ Klebsiela Spp(8) } \\
\hline & TASH(04) & S, G, TE, SXT, GM, CIP, AN & 1 & 7 \\
\hline & & CF, AMC, CRO & 3 & 3 \\
\hline & $\mathrm{ZMH}(03)$ & SXT, G, CRO, C, CF, AMC & 3 & 6 \\
\hline & Private(01) & $\mathrm{CF}, \mathrm{AMC}$ & 1 & 3 \\
\hline \multicolumn{5}{|l|}{ Citrobacter Spp(7) } \\
\hline & TASH(02) & $\mathrm{G}, \mathrm{CF}, \mathrm{AN}, \mathrm{AM}, \mathrm{AMC}$ & 2 & 6 \\
\hline & $\mathrm{ZMH}(04)$ & $\mathrm{S}, \mathrm{CRO}, \mathrm{CF}, \mathrm{AM}, \mathrm{AMC}$ & 1 & 5 \\
\hline & & G & 3 & 1 \\
\hline & Private(1) & $\mathrm{S}, \mathrm{G}, \mathrm{CRO}, \mathrm{CF}, \mathrm{AN}, \mathrm{AMC}$ & 1 & 6 \\
\hline
\end{tabular}

$\mathrm{NRP}=$ Number with resistance pattern, $\mathrm{TNatbR}=$ Total number of antimicrobial to which isolate is resistant, $\mathrm{TE}=\mathrm{Tetracycline}, \mathrm{SXT}=$ Sulphamethoxazole+Trimethoprim, S = Streptomycin, GM = Gentamicin, CRO = Ceftriaxone, CIP = Ciprofloxacin, CF = Cephalothin, C = Chloramphenicol, $\mathrm{AN}=$ Amikacin, $\mathrm{AMC}=$ Amoxacillin + Clavulanic Acid, $\mathrm{AM}=$ Ampicillin, $\mathrm{VA}=$ Vancomycin, $\mathrm{P}=\mathrm{Penicillin}, \mathrm{ERY}=\mathrm{Erythromycin}, \mathrm{OX}=$ Oxacillin, DA = Clindamycin, G = Sulfisoxazole, AN = Amikacin, TASH = Tikur Anbesa Specialized Hospital, ZMH = Zewditu Memorial Hospital

\section{Discussion}

Presence of high load of bacteria in the urine of pregnant women, is reported to lead to complications like pyelonephritis, septicemia and, may also result in low birth weight and still birth [10]. The current study showed that the prevalence of ASBU among pregnant women attending antenatal care services in Addis Ababa was 15.7\% which is lower than the prevalence reported from Northern Ethiopia (21.2\%) [28], south Ethiopia (18.8\%)[15] and Nigeria (24.7\%) [13]. It is however higher than the prevalence reported from Ghana (5.5\%) [14] and North West Ethiopia 9.8\% [29]. The possible reason for such difference could be due to variation in care during urine collection, difference in socioeconomic status, and genital hygienic practices among pregnant women from different background[30, 31]. 
Although previous reports showed that increased maternal age, multi-parity[30, 32], sexual activity[14], past history of urinary tract infection[33] are associated with occurrence of ASBU among pregnant women, our data did not replicate the association. This may be attributed partly to small sample.

The most frequently isolated bacterial uropathogens in this study is $E$. coli $17(30.6 \%)$, which is in agreement with previous studies elsewhere [16, 33, 34]. However, it is contrary to the study from India, which reported Staphylococcus aurous as the most prevalent pathogen[35]. None of the pregnant women with ASBU in the current study were positive for $S$. aureus unlike most of the previous studies [16, 34]. Previous studies also showed that $S$. aureus bacteriuria is unusual except in patients with predisposing conditions for ascending colonization such as history of urinary obstruction, urinary catheter, recent urological surgical procedures, malignancy and recent hospitalization [36-38].

Proteus spp., 13(23.2\%) is the second most frequently isolated bacteria among pregnant women in this study. Similar high rate of occurrence of Proteus spp. has been reported in previous studies $[14,16]$. The enzyme urease produced by Proteus spp. hydrolyzes urea present in excess amount in the urine producing ammonia that leads to increased $\mathrm{pH}$ of the urine which favors precipitation of stones and other UTI complications[39].

The only gram positive bacteria isolated in the current study was Enterococcus spp., 11(19.6\%) which is in line with previous reports from Gana and Kenya [14, 34], whereas previous studies from Ethiopia on pregnant women with ASBU did not report Enterococcus spp. [15, 16]. This difference may be due to difference in socio-economic characteristics, season of the study, clinical and background characteristics.

Overall, rate of occurrence of resistance to antimicrobials tested in the current study is variable when compared to previous studies. Some of the isolates were also resistant to ciprofloxacin and ceftriaxone, antimicrobials commonly used for treatment of various infectious pathogens. Compared to isolates from pregnant women with ASBU previously in Ethiopia, high rate of resistance to ampicillin was recorded in the current study among gram negative isolates. For instance only $68.8 \%$ of isolates of $E$. coli were resistant to ampicillin [15] in previous study from south Ethiopia whereas $100 \%$ resistance was recorded in the current study. On the other hand, same previous study reported $43.8 \%$ resistance to ceftriaxone while only $17.8 \%$ resistance was detected in the current study. A study from north Ethiopia reported $100 \%$ resistance to ampicillin and $5.2 \%$ resistance to ceftriaxone [16]. Another study from Kenya also reported $74.1 \%$ resistance of $E$. coli to cefotaxime another third generation cephalosporin which is very high compared to $18.2 \%$ resistance to ceftriaxone in the current study[34]. Resistance to sulfamethoxazole + trimethoprim is only $5.9 \%$ in $E$. coli isolates in the current study whereas high as $47.4 \%$ and $82.2 \%$ resistance was reported in previous studies $[15,16]$, in Ethiopia. However, none of the $E$. coli isolates from study in Uganda were resistant to Sulfamethoxazole + trimethoprim[40].

High level of resistance to penicillin, oxacillin, and clindamycin was also detected in Enterococus isolates in this study. Recent study from Uganda, reported $50 \%$ resistance to ciprofloxacin and $100 \%$ resistance to amoxicillin + clavulanic acid whereas in the current study, only $9.1 \%$ and $54.5 \%$ resistance was detected, respectively[40]. The reason for difference among studies could be due to variation in level of irrational use of antimicrobials among pregnant women and the community in each study area.

Most of the bacterial isolates in the current study were resistant to two or more antimicrobials tested. Previous study from Ambo town also reported resistance to 2 or more antimicrobials in all of the bacterial isolates from pregnant women with symptomatic urinary tract infection and those with ASBU[41]. Detection of high level resistance to ampicillin in all of E. coli and Citrobacter spp. in the current study shows minimal use of this antimicrobial to treat infections caused by these organisms in the area. The finding of this study revealed that $27.3 \%$ of the Enterococcus spp., isolates were resistant to vancomycin, which is lower than study finding from India that reported over $80 \%$ resistance [42]. This difference may be due to difference in socio-demographic, background characteristics, and difference in awareness level of transmission and/or prevention of infectious bacteria, and/or difference in extent, frequency and/or manner of antimicrobial use. Some of the isolates detected in the current study were multidrug resistant to about 6-7 antimicrobials in the case of gram negative organisms and one of the Enterococcus isolate was resistant to 9 antimicrobials suggesting rapid action on prudent use of antimicrobials in the study area.

Even though, the data generated from this study gives significant scientific evidence on status of ASBU in the study area, the fact that the number of pregnant women involved in the study was small and the interview was based on self-report rendered to recall bias and social desirability bias. Henc, it may not be generalized to the wider community.

\section{Conclusions}

This study showed $15.7 \%$ prevalence of ASBU in pregnant women in Addis Ababa with the possible risk of developing to symptomatic UTI and associated complication. High rate of resistance to antimicrobials commonly used to treat UTI infection has been recorded in bacterial isolates. Hence routine screening for ASBU during antenatal visit is likely to result in early treatment and minimize complication to the mother and fetus. It is also recommended to assess sensitivity of isolates to commonly prescribed antimicrobials rather than treating empirically.

\section{Abbreviations}

ASBU: Asymptomatic bacteriuria

CFU: Colony forming unit

CLSI: Clinical Laboratory Standards Institute 
MDR: Multi-drug resistant

UTI: Urinary tract infection

\section{Declarations}

\section{Ethics approval and consent to participate}

Study was approved by the Institutional Review Board of Aklilu Lemma Institute of Pathobiology, Addis Ababa University and Addis Ababa Health Bearoue. Permission was obtained from administration office of each of the study hospital's health care specialty centers. Purpose of the study was clearly explained to the health care professionals working in the antenatal clinics. Informed verbal consent was obtained from each study participant before initiation of data and sample collection after purpose of the study was explained. The study participants were informed that their participation is not mandatory and they can refuse to participate or withdraw from the study at any time.

\section{Consent for publication}

Not applicable

\section{Availability of data and materials}

All data that were used to support the findings of this study are included within the article.

\section{Competing interests}

The authors declare that they have no competing interests.

\section{Funding}

This study was supported by Addis Ababa University.

\section{Authors' Contributions}

KB and TE participated in conception of the study. KB was involved in sample collection, laboratory investigation and preparation of the draft manuscript. GM contributed in the study design, data summarization and critically reviewed the draft manuscript. HA participated in laboratory work. WA participated in preparation of the manuscript. All authors read and approved the final manuscript.

\section{Acknowledgments}

The authors would like to thank Addis Ababa University, for funding the study. We are grateful for cooperation of the health personnel at each antenatal center for their collaboration during data and sample collection. Technical assistance of Azeb Teklu during laboratory work is highly appreciated.

\section{References}

1. Thomas J. Hannan MT, Kylie J. Mansfield, Kate H. Moore, Mark A., Schembri aSJH: Host-Pathogen Checkpoints and Population Bottlenecks in Persistent and Intracellular Uropathogenic E. coli Bladder Infection. FEMS Microbiology 2012, 36(3):616-640.

2. Gonzalez CM, Schaeffer AJ: Treatment of urinary tract infection: what's old, what's new, and what works. World Journal of Urology 1999 , 17(6):372-382.

3. Anuli S. John CIMaBA: A review on the prevalence and predisposing factors responsible for urinary tract infection among adults. European Journal of Experimental Biology 2016, 6(4):7-11.

4. M M, S G: Study on urinary tract infection among females of reproductive age group in a rural area of Kancheepuram district, Tamil Nadu. International Journal Of Community Medicine And Public Health 2017, 4(10):3915.

5. Al-Shaikh AA-BaG: Recurrent Urinary Tract Infections Management in Women. Sultan Qaboos University Med Journal 2013, $13(3): 359-367$.

6. Tchente Nguefack C, Okalla Ebongue C, Nouwe Chokotheu C, Ebong Ewougo C, Nana Njamen T, Mboudou E: Clinical presentation, risk factors and pathogens involved in bacteriuria of pregnant women attending antenatal clinic of 3 hospitals in a developing country: a cross sectional analytic study. BMC Pregnancy Childbirth 2019, 19(1):143. 
7. Glaser AP, Schaeffer AJ: Urinary Tract Infection and Bacteriuria in Pregnancy. Urol Clin North Am 2015, 42(4):547-560.

8. Mor G, Cardenas I: The immune system in pregnancy: a unique complexity. Am J Reprod Immunol 2010, 63(6):425-433.

9. Hazhir S: Asymptomatic bacteriuria in pregnant women. Urol J 2007, 4(1):24-27.

10. Sheiner E, Mazor-Drey E, Levy A: Asymptomatic bacteriuria during pregnancy. J Matern Fetal Neona 2009, 22(5):423-427.

11. Renko M, Tapanainen $\mathrm{P}$, Tossavainen P, Pokka T, Uhari M: Meta-analysis of the significance of asymptomatic bacteriuria in diabetes. Diabetes Care 2011, 34(1):230-235.

12. Karunajeewa H, McGechie D, Stuccio G, Stingemore N, Davis WA, Davis TM: Asymptomatic bacteriuria as a predictor of subsequent hospitalisation with urinary tract infection in diabetic adults: The Fremantle Diabetes Study. Diabetologia 2005, 48(7):1288-1291.

13. Onu FA, Ajah LO, Ezeonu PO, Umeora OU, Ibekwe PC, Ajah MI: Profile and microbiological isolates of asymptomatic bacteriuria among pregnant women in Abakaliki, Nigeria. Infect Drug Resist 2015, 8:231-235.

14. Labi AK, Yawson AE, Ganyaglo GY, Newman MJ: Prevalence and Associated Risk Factors of Asymptomatic Bacteriuria in Ante-Natal Clients in a Large Teaching Hospital in Ghana. Ghana Med J 2015, 49(3):154-158.

15. Tadesse E, Teshome M, Merid Y, Kibret B, Shimelis T: Asymptomatic urinary tract infection among pregnant women attending the antenatal clinic of Hawassa Referral Hospital, Southern Ethiopia. BMC Res Notes 2014, 7:155.

16. Tadesse S, Kahsay T, Adhanom G, Kahsu G, Legese H, A GW, Derbie A: Prevalence, antimicrobial susceptibility profile and predictors of asymptomatic bacteriuria among pregnant women in Adigrat General Hospital, Northern Ethiopia. BMC Res Notes 2018, 11(1):740.

17. Foxman B: Urinary Tract Infection Syndromes: Occurrence, Recurrence, Bacteriology, Risk Factors, and Disease Burden. Infectious Disease Clinics of North America 2014, 28(1):1-13.

18. Kline KA, Schwartz DJ, Lewis WG, Hultgren SJ, Lewis AL: Immune activation and suppression by group B streptococcus in a murine model of urinary tract infection. Infection and immunity 2011, 79(9):3588-3595.

19. Willy Fred N, Gichuhi JW, Mugo NW: Prevalence of Urinary Tract Infection, Microbial Aetiology, and Antibiotic Sensitivity Pattern among Antenatal Women Presenting with Lower Abdominal Pains at Kenyatta National Hospital, Nairobi, Kenya. The Open Access Journal of Science and Technology 2015, 3.

20. Smaill FM, Vazquez JC: Antibiotics for asymptomatic bacteriuria in pregnancy. Cochrane Database Syst Rev 2015(8):CD000490.

21. Rudick CN, Taylor AK, Yaggie RE, Schaeffer AJ, Klumpp DJ: Asymptomatic Bacteriuria Escherichia coli Are Live Biotherapeutics for UTI. PLOS ONE 2014, 9(11):e109321.

22. Tadesse S, Kahsay T, Adhanom G, Kahsu G, Legese H, A GW, Derbie A: Prevalence, antimicrobial susceptibility profile and predictors of asymptomatic bacteriuria among pregnant women in Adigrat General Hospital, Northern Ethiopia. BMC research notes 2018, $11(1): 740$.

23. Umar M, Aa Y, Yusuf G, Tafinta I, Aliko A, Jobbi Y, Lawal G: Biochemical characterization and antimicrobial susceptibility trends of Proteus mirabilis isolated from patients suspected with urinary tract infections attending Sickbay Hospital, Zaria, Kaduna, Nigeria. ANNALS OF BIOLOGICAL SCIENCES 2016, 2016(2):1-8.

24. Hansen DS, Aucken HM, Abiola T, Podschun R: Recommended test panel for differentiation of Klebsiella species on the basis of a trilateral interlaboratory evaluation of 18 biochemical tests. Journal of clinical microbiology 2004, 42(8):3665-3669.

25. Flores Abuxapqui JJ, Suárez Hoil GJ, Heredia Navarrete MR, Puc Franco MA, Vivas Rosel ML: Four biochemical tests for identification of probable enteroinvasive Escherichia coli strains. Rev Latinoam Microbio/ 1999, 41(4):259-261.

26. CLSI: M100: Performance standards for antimicrobial susceptibility testing: twenty-third informational supplement. . In., 28th Edition edn. Wayne, PA; 2018.

27. Magiorakos AP, Srinivasan A, Carey RB, Carmeli Y, Falagas ME, Giske CG, Harbarth S, Hindler JF, Kahlmeter G, Olsson-Liljequist B et al: Multidrugresistant, extensively drug-resistant and pandrug-resistant bacteria: an international expert proposal for interim standard definitions for acquired resistance. Clinical microbiology and infection : the official publication of the European Society of Clinical Microbiology and Infectious Diseases 2012, 18(3):268-281.

28. Tadesse S, Kahsay T, Adhanom G, Kahsu G, Legese H, A GW, Derbie A: Correction to: Prevalence, antimicrobial susceptibility profile and predictors of asymptomatic bacteriuria among pregnant women in Adigrat General Hospital, Northern Ethiopia. BMC Res Notes 2018, 11(1):798.

29. Tadesse A, Negash M, Ketema LS: Asymtomatic bacteriuria in pregnancy: assesment of prevlence, microbial agents and ther antimicrobial sensitivty pattern in Gondar Teaching Hospital, north west Ethiopia. Ethiop Med J 2007, 45(2):143-149.

30. Fatima N, Ishrat S: Frequency and risk factors of asymptomatic bacteriuria during pregnancy. J Coll Physicians Surg Pak 2006, $16(4): 273-275$.

31. Enayat K, Fariba F, Bahram N: Asymptomatic bacteriuria among pregnant women referred to outpatient clinics in Sanandaj, Iran. International Braz $J$ Urol 2008, 34(6).

32. Amit Ranjan K-SS, Matta N, Chokkakula S, Khatoon-Ansari R: Prevalence of UTI among Pregnant Women and Its Complications in Newborns. Indian Journal of Pharmacy Practice 2017, 10(1).

33. Farazia A, Jabbariasl M: Asymptomatic bacteriuria in pregnancy in the central region of Iran: Frequency, risk factors, and causative organisms. Clinical Epidemiology and Global Health 2019, 7:309-312. 
34. Ayoyi AO, Kikuvi G, Bii C, Kariuki S: Prevalence, aetiology and antibiotic sensitivity profile of asymptomatic bacteriuria isolates from pregnant women in selected antenatal clinic from Nairobi, Kenya. Pan Afr Med J 2017, 26:41.

35. Singh B, Katiyar D, Tilak R, Srivastava R, Chauhan R: Prevalence of Urinary Tract Infection Causing Microorganism and Determination of Susceptibility to Antibiotic among Slum Women of District Varanasi, India. International Journal of Current Microbiology and Applied Sciences 2018, 7:3483-3497.

36. Al Mohajer M, Darouiche RO: Staphylococcus aureus Bacteriuria: Source, Clinical Relevance, and Management. Curr Infect Dis Rep 2012, 14(6):601-606.

37. Choi SH, Lee SO, Choi JP, Lim SK, Chung JW, Jeong JY, Woo JH, Kim YS: The clinical significance of concurrent Staphylococcus aureus bacteriuria in patients with S. aureus bacteremia. J Infect 2009, 59(1):37-41.

38. Asgeirsson H, Kristjansson M, Kristinsson KG, Gudlaugsson O: Clinical significance of Staphylococcus aureus bacteriuria in a nationwide study of adults with S. aureus bacteraemia. J Infect 2012, 64(1):41-46.

39. Armbruster CE, Mobley HLT, Pearson MM: Pathogenesis of Proteus mirabilis Infection. EcoSal Plus 2018, 8(1).

40. Nteziyaremye J, Iramiot SJ, Nekaka R, Musaba MW, Wandabwa J, Kisegerwa E, Kiondo P: Asymptomatic bacteriuria among pregnant women attending antenatal care at Mbale Hospital, Eastern Uganda. PLoS One 2020, 15(3):e0230523.

41. Gessese YA, Damessa DL, Amare MM, Bahta YH, Shifera AD, Tasew FS, Gebremedhin EZ: Urinary pathogenic bacterial profile, antibiogram of isolates and associated risk factors among pregnant women in Ambo town, Central Ethiopia: a cross-sectional study. Antimicrobial resistance and infection control 2017, 6:132.

42. Bose AK, Sreekumary, Pulikkottil, Sobha: Microbiological profile of asymptomatic bacteriuria in pregnancy. International Journal of Reproduction, Contraception, Obstetrics and Gynecology 2017, 6:1352. 